\title{
The Incidence of Cervical Disease in Women of Different Age Groups in the Republic of Sakha (Yakutia)
}

\author{
Maria P. Kirillina, $\mathrm{PhD}^{1^{*}}$; Sargylana I. Sofronova, $\mathrm{PhD}^{2}$; Irina V. Kononova, $\mathrm{PhD}^{2}$; \\ Anna K. Ivanova $^{1}$; Darima K. Garmaeva, $\mathrm{PhD}, \mathrm{ScD}^{1}$; Elena L. Lushnikova, $\mathrm{PhD}, \mathrm{ScD}^{3}$ \\ ${ }^{I}$ North-Eastern Federal University named after MK Ammosov, Yakutsk, Russia \\ ${ }^{2}$ Yakut Research Centre for Complex Medical Problems, Yakutsk, Russia \\ ${ }^{3}$ Federal Research Center of Fundamental and Translational Medicine, Novosibirsk, Russia
}

\begin{abstract}
The purpose of this study was to investigate the incidence of cervical disease in women of different age groups in the Republic of Sakha (Yakutia).

Materials and Methods: The cytological material of the cervix of 7,600 women aged between 18 and 88 years was analyzed in the laboratory of pathomorphology, histology and cytology. The material of the cytological study consisted of smears of cervical mucosa and the cervical canal, stained according to the method of Romanovsky-Giemsa. The study was conducted with subjects grouped according to age: Group 1 (18-29), Group 2 (30-44), Group 3 (45-59), and Group 4 (60-74).

Results: According to the results of cytological analysis, inflammatory diseases of the cervix uteri were diagnosed in 4,629/61\% cases. Among age groups, the highest rate of inflammatory diseases of the cervix uteri was registered in Group 1 and Group 2. Benign cervical lesions were found in 563/7.4\% cases with the highest incidence in Groups 1 and 2 . The most frequently diagnosed pathology was squamous cell metaplasia with maximum frequency in Group 2 and Group 1. Cervical intraepithelial neoplasia (CIN) was detected in 359/4.7\% cases. CIN I, CIN II and CIN III were registered in 220/61.3\%, 84/24.5\%, and 38/10.6\% women, respectively. At the same time, the maximum frequency of dysplasia was noted in Group 1 and Group 2. Thus, results obtained indicate a high incidence of cervical disease in women of reproductive age.(International Journal of Biomedicine. 2019;9(1):39-42.)
\end{abstract}

Key Words: cervical disease $\bullet$ inflammatory diseases $\bullet$ benign cervical lesions $\bullet$ cervical intraepithelial neoplasia

\section{Introduction}

The problem of cervical diseases (CD) is one of the topical issues in modern gynecology, and it has great importance for preventing the emergence and development of malignant tumors. The frequency of $\mathrm{CD}$ is very high and has no tendency to decrease: cervical pathology occupies a significant place in the structure of reproductive system diseases, as it is found in $15 \%-20 \%$ of women of reproductive age and $5 \%-9 \%$ of women of menopausal age. ${ }^{(1)}$ Worldwide, cervical cancer (CC) is the fourth most frequent cancer in women, with an estimated 530,000 new cases in 2012 representing 7.5\% of all female cancer deaths. CC is by far the most common HPV-related disease. ${ }^{(2)}$ Most cervical carcinomas are etiologically related to

*Corresponding author: Maria P. Kirillina, PhD. NorthEastern Federal University named after MK Ammosov, Yakutsk, Russia.E-mail: kirillinamp@mail.ru the human papillomavirus (HPV) and about $70 \%$ of all cervical carcinomas are caused by 2 types of high-risk HPV, 16 and 18. (3) Once infected by HPV, cervical neoplasia undergoes a stepwise progression starting from preinvasive lesions that can be detected by screening and cured with complete excision. ${ }^{(4)}$ In developed countries, programs are in place that enable women to get screened, making most pre-cancerous lesions identifiable at stages when they can easily be treated. Early treatment prevents up to $80 \%$ of CC in these countries. ${ }^{(2)}$

The purpose of this study was to investigate the incidence of cervical disease (CD) in women of different age groups in the Republic of Sakha (Yakutia).

\section{Materials and Methods}

The purpose of this study was to investigate the incidence of cervical disease (CD) in women of different age groups in the Republic of Sakha (Yakutia). The cytological 
material of the cervix of 7,600 women aged between 18 and 88 years, who applied to various medical institutions of the Republic of Sakha (Yakutia) $(\mathrm{RS}(\mathrm{Y}))$ for preventive and diagnostic purposes during 2017, was analyzed in the laboratory of pathomorphology, histology and cytology of the NEFU Medical Institute Clinic.

The material of the cytological study consisted of smears of cervical mucosa and the cervical canal, stained according to the method of Romanovsky-Giemsa. The study was conducted with subjects grouped according to age: Group 1 (18-29), Group 2 (30-44), Group 3 (4559), and Group 4 (60-74). Bokhman's classification (1976) was used to assign a diagnosis. ${ }^{(5)}$ According to Bokhman's classification, pathological processes in the cervix are divided into background processes (benign cervical lesions [BCL]), precancerous conditions (CIN II-III) and cancer.

\section{Results and Discussion}

Cytological material from 7,600 women was distributed as follows: Group $1-2,645 / 34.8 \%$, Group $2-2,315 / 30.4 \%$, Group $3-1,840 / 24.2 \%$, and Group $4-800 / 10.5 \%$. According to the results of cytological analysis, inflammatory diseases of the cervix uteri (IDCU) were diagnosed in 4,629/61\% cases (Fig.1).

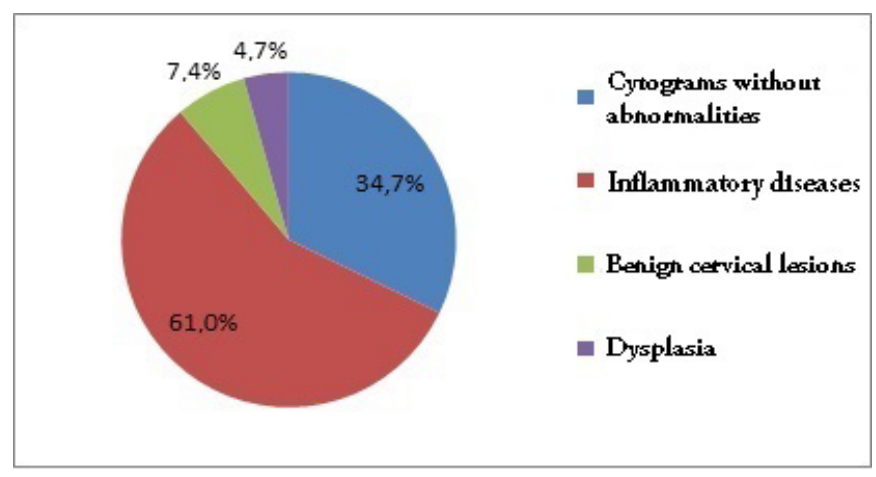

Fig.1. Results of cytological analysis.

Table 1.

The incidence of inflammatory diseases of the cervix in different age groups (in $n / \%$ )

\begin{tabular}{|l|c|c|c|c|c|}
\hline & Group 1 & Group 2 & Group 3 & Group 4 & Total \\
\hline $\begin{array}{l}\text { Inflammatory } \\
\text { process }\end{array}$ & $540 / 29.8$ & $348 / 19.2$ & $542 / 29.9$ & $379 / 20.9$ & $1809 / 39$ \\
\hline Flora dysbiosis & $740 / 40.7$ & $693 / 38.2$ & $337 / 18.5$ & $45 / 2.5$ & $1815 / 39.2$ \\
\hline $\begin{array}{l}\text { Candidal } \\
\text { colpitis }\end{array}$ & $57 / 49.5$ & $38 / 33$ & $17 / 14.8$ & $3 / 2.6$ & $115 / 2.5$ \\
\hline $\begin{array}{l}\text { Trichomonas } \\
\text { colpitis }\end{array}$ & $29 / 49.1$ & $16 / 27.1$ & $13 / 22$ & $1 / 1.7$ & $59 / 1.3$ \\
\hline $\begin{array}{l}\text { Follicular } \\
\text { cervicitis }\end{array}$ & $47 / 49.5$ & $25 / 26.3$ & $13 / 13.7$ & $10 / 10.5$ & $95 / 2$ \\
\hline $\begin{array}{l}\text { Chlamydial } \\
\text { infection }\end{array}$ & $14 / 29.7$ & $18 / 38.3$ & $12 / 25.5$ & $3 / 6.4$ & $47 / 1$ \\
\hline $\begin{array}{l}\text { Viral infection } \\
\text { (indirect signs) }\end{array}$ & $269 / 39$ & $269 / 39$ & $131 / 19$ & $20 / 2.9$ & $689 / 14.9$ \\
\hline Total & $1696 / 36.6$ & $1407 / 30.4$ & $1065 / 23$ & $461 / 9.9$ & $4629 / 61$ \\
\hline
\end{tabular}

Among age groups, the highest rate of IDCU was registered in Group 1 (1696/36.6\% cases) and Group 2 (1407/30.4\% cases) (Table 1). In $1815 / 39.2 \%$ women, flora dysbiosis (bacterial vaginosis (BV) and Lactobacillus bacteremia (LB)) were found. The maximum frequency of flora dysbiosis was detected in Group 1 (740/40.7\%) and Group 2 (693/38.2\%). In BV, the cytogram presents an abundance of coccobacilli, "clue cell" and a small number of leukocytes (Fig. 2). Inflammatory processes have been identified in 1809/39\% cases. The highest incidence was found in Group 1 (540/29.8\%) and Group 3 (542/29.9\%).

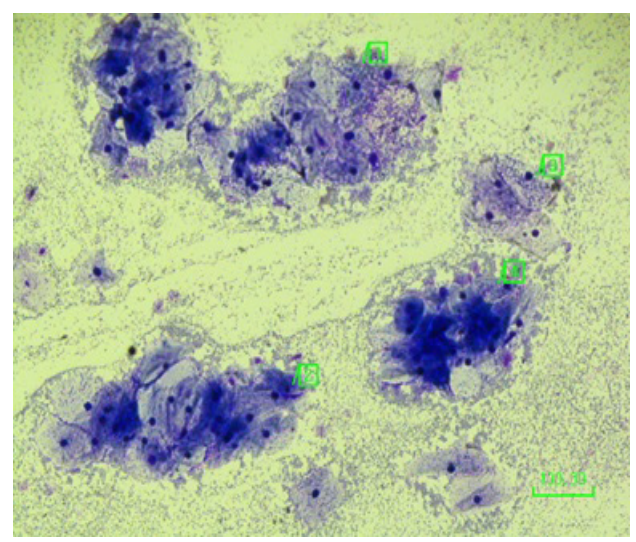

Fig. 2. Bacterial vaginosis: an abundance of coccobacilli, "clue cell" and a small number of leukocytes; magnification $\times 200$.

Currently, among sexually transmitted infections, the human papillomavirus (HPV) represents the greatest interest. HPV preferentially infects cells in the cervical transformation zone, an area of active cell turnover. Basal cells, which feature the HPV receptor, are a natural target for infection. The virus remains in the cell in a latent state until activation causes viral replication and squamous dysplasia. Low-grade squamous intraepithelial lesion/cervical intraepithelial neoplasia 1 (LSIL/CIN 1) is characterized by koilocytotic atypia, nuclear enlargement, hyperchromasia, and perinuclear cytoplasmic clearing (Figures 3.4). These features are the result of viral proteins that affect DNA synthesis and the structure of intermediate filaments in the host cell cytoplasm. ${ }^{(4)}$ Indirect signs of viral infection were detected in $689 / 14.9 \%$ women, with a maximum frequency in Groups 1 and 2 (Table 1, Fig.3). These women were recommended to have HPV tests.

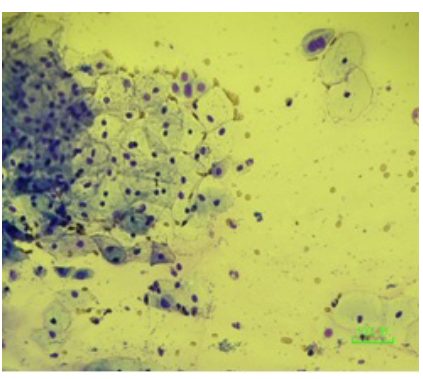

(3)

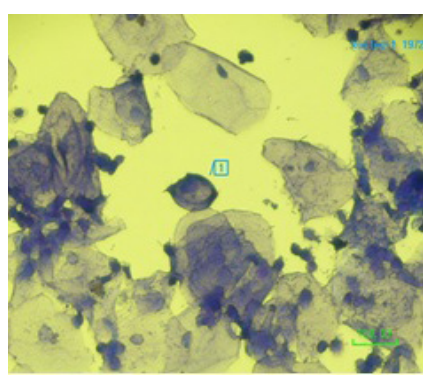

(4)
Figures 3,4. Binuclear cells and "kissing" nuclei in cervical smear for HPV infection (conventional smear) and koilocyte in liquid-based cytology (stained by Romanovsky-Giemsa); magnification $x 400$. 
Candidal colpitis was registered in $115 / 2.5 \%$ women. In smears, budding yeast cells, spores, and pseudomycelium were found (Fig.5). Follicular cervicitis was detected in $2 \%$ of cases, with the highest frequency in Group $1(47 / 49.5 \%)$ and Group 2 (25/26.3\%). Cytological results of this pathology were characterized by the presence of lymphoid elements (Fig.6).

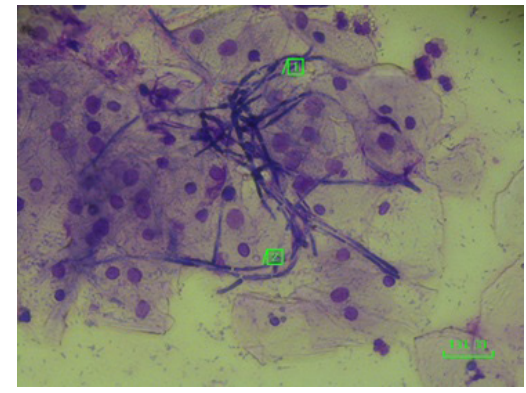

Fig. 5. Candidiasis. Pseudomycelium and fungal spores in the cervical smear, magnification $\times 400$.

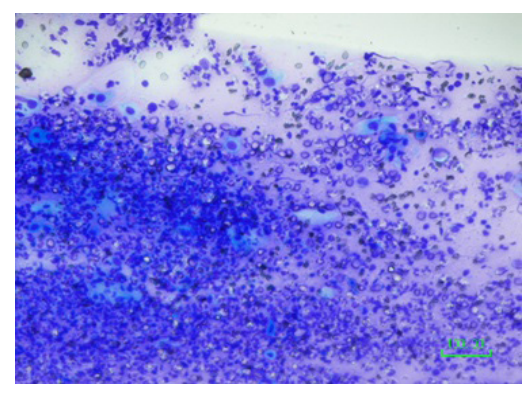

Fig. 6. Follicular cervicitis; magnification $x 200$.

Trichomonas colpitis was detected in $1.3 \%$ of women, with the highest frequency in Group 1 (49.1\%) (Table 1, Fig.7). Urogenital chlamydia was detected in $1 \%$ of women with the highest frequency in Group 2 (38.3\%) (Figures $8,9)$. It should be noted that the data of cytological studies for the detection of chlamydial infection are only indicative and should be supplemented by other research methods (immunofluorescence analysis, PCR, etc.).

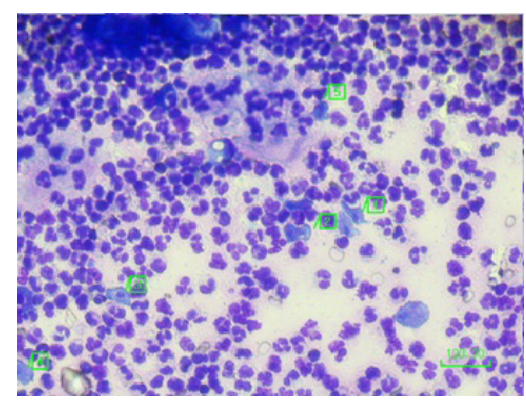

Fig. 7. Trichomonas colpitis: Trichomonas and leukocytes in a ectocervical smear; magnification $\times 400$.

BCLs include hyperplastic processes associated with hormonal disorders, as well as inflammatory and posttraumatic processes. The frequency of BCLs in different age groups is presented in Table 2. The highest incidence of BCLs was found in women of Group 2 (212/37.6\%) and Group 1 $(187 / 33.2 \%)$. The most frequently diagnosed pathology was squamous cell metaplasia (74\%) with maximum frequency in Group 2 (35.7\%) and Group 1 (30.4\%), obviously due to the intense influence of sex hormones (estrogens) in women of active reproductive age. Proliferation of glandular epithelial cells and cervical hyperkeratosis were registered much less frequently: $12 \%$ and $7.1 \%$, respectively.

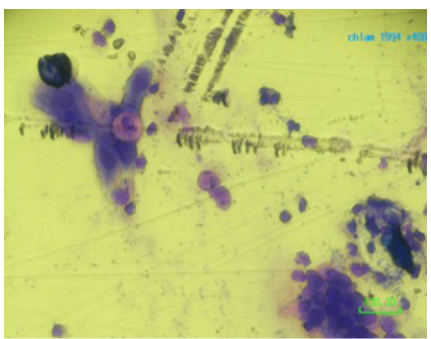

(8)

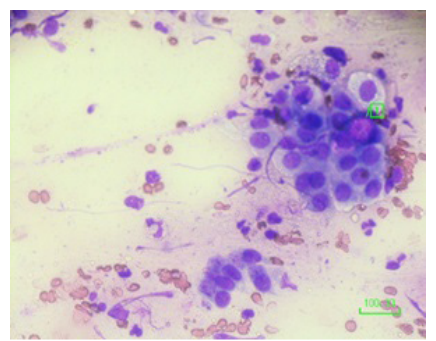

(9)
Figures 8, 9. Chlamydial infection: the layers of metaplastic epithelial cells with vacuoles containing inclusions of various sizes; magnification $x 400$.

Table 2.

Benign cervical lesions in different age groups (in n/\%)

\begin{tabular}{|l|c|c|c|c|c|}
\hline & Group 1 & Group 2 & Group 3 & Group 4 & Total \\
\hline Cervical hyperkeratosis & $12 / 30$ & $16 / 40$ & $10 / 25$ & $2 / 5$ & $40 / 7.1$ \\
\hline $\begin{array}{l}\text { Squamous cell metaplasia. } \\
\text { Microglandular hyperplasia }\end{array}$ & $127 / 30.4$ & $149 / 35.7$ & $102 / 24.5$ & $39 / 9.3$ & $417 / 74$ \\
\hline $\begin{array}{l}\text { Proliferation of } \\
\text { glandular epithelial cells }\end{array}$ & $35 / 51.5$ & $30 / 44.1$ & $2 / 2.9$ & $1 / 1.5$ & $68 / 12$ \\
\hline $\begin{array}{l}\text { Dysplasia (atypical } \\
\text { hyperplasia) }\end{array}$ & $13 / 34.2$ & $17 / 44.7$ & $7 / 18.4$ & $1 / 2.6$ & $38 / 6.7$ \\
\hline Total & $187 / 33.2$ & $212 / 37.6$ & $121 / 21.5$ & $43 / 7.6$ & $563 / 7.4$ \\
\hline
\end{tabular}

Cervical intraepithelial neoplasia (or dysplasia) (CIN) was detected in $359 / 4.7 \%$ cases. Among them, CIN I, CIN II and CIN III were registered in $220 / 61.3 \%, 84 / 24.5 \%$, and $38 / 10.6 \%$ women, respectively (Fig. 10). At the same time, the maximum frequency of dysplasia was noted in Group $1(32 \%)$ and Group 2 (33\%). In Groups 3 and 4, dysplasia was found in $87(24,2 \%)$ and 39 (11\%) cases, respectively.

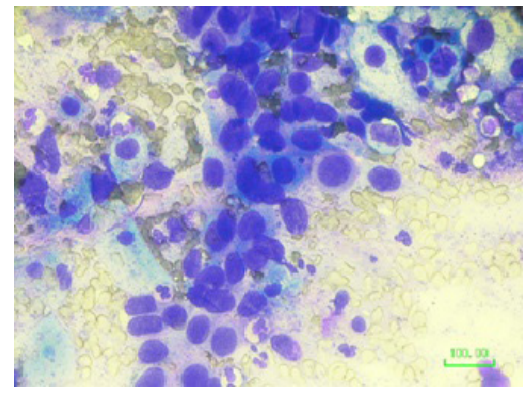

Fig. 10. Parabasal cells: CIN II; magnification $\times 400$.

Low-grade squamous lesions (CIN I), recognized as primarily the histologic manifestation of HPV infection, 
usually resolve, but must be followed within 12 months to make sure that they do not progress to CIN 2 (moderate changes) and CIN 3 (high-grade changes). Depending on age groups (Fig.11), we found that the frequency of CIN I and CIN II was the same for women of Group $1(19.7 \%$ and $7.2 \%)$ and Group 2 (19.2\% and 7.5\%). CIN III was found in 3.3\%, $3.9 \%$, and $3.1 \%$ for Groups 1, 2, and 3, respectively. Severe dysplasia with a transition to cancer was diagnosed in $4 / 1.1 \%$ women: two cases in Group 2, one case in Group 3, and one case in Group 4. Thus, our results indicate a high incidence of dysplasia in women of reproductive age.

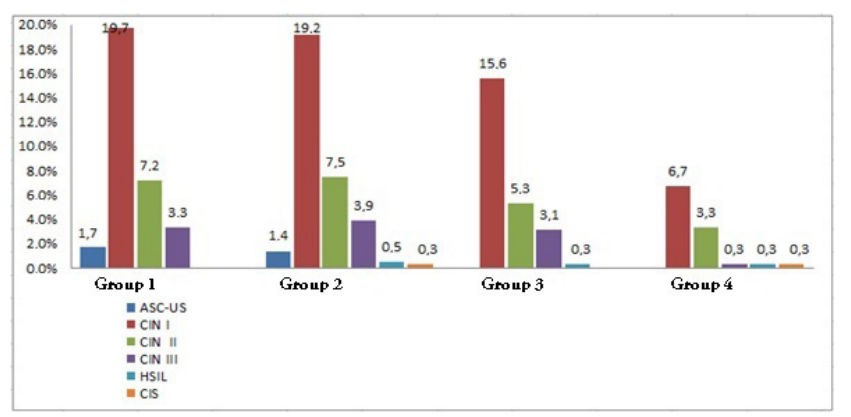

Fig. 11. The incidence of cervical dysplasia in different age groups.

As is well known, HPV infection increases the risk of dysplasia by 10 times. In the examined group of women, a combination of dysplasia with indirect symptoms of a viral infection was found in 207/57.6\% cases. Taking into account that only a primary cytological examination was carried out in our Medical Institute Clinic, it is impossible to give a direct conclusion about the relationship between cervical dysplasia and a virus carrier. If a suspicious cervical lesion is identified in the first stage of the survey, the second stage of examination (colposcopy with target cervical biopsy, PCR methods for morphological verification of the diagnosis, histological examination) must be performed.

There have been a number of technological advances in CC screening since the introduction of Pap testing more than 60 years ago. ${ }^{(6)}$ Among them, the implementation of routine screening programs is recognized as a public health success, whereas liquid-based cytology (LBC) represents a significant shift in testing methodology. This shift from conventional cytology to LBC has occurred due to improvements in sample quality, reproducibility, sensitivity, and specificity, as well as the ability to perform reflex molecular testing. ${ }^{(7,8)}$ Pre-cancerous lesions detected during $\mathrm{CC}$ screening can easily be treated and cancer avoided. The new USPSTF ${ }^{(9)}$ recommendations emphasize that the choice of screening strategy should consider the balance of benefit (disease detection) and potential harms (more frequent follow-up testing, invasive diagnostic procedures, and unnecessary treatment in women with falsepositive results) and involve shared decision making between patients and their health care providers.

\section{Competing Interests}

The authors declare that they have no competing interests.

\section{References}

1. Prilepskaya V. N. Cervix uteri, vulva and vagina diseases: Clinical lectures, V.3, M.: Medpressform; 2003.

2. WHO. Human papillomavirus (HPV) and cervical cancer. 15 February 2018. Available from: https://www.who.int/news$\mathrm{room} /$ fact-sheets/detail/human-papillomavirus-(hpv)-andcervical-cancer

3. Muñoz N, Bosch FX, de Sanjosé S, Herrero R, Castellsagué X, Shah KV, et al.; International Agency for Research on Cancer Multicenter Cervical Cancer Study Group. Epidemiologic classification of human papillomavirus types associated with cervical cancer. N Engl J Med. 2003 Feb 6;348(6):518-27.

4. Park KJ, Soslow RA. Current concepts in cervical pathology. Arch Pathol Lab Med. 2009;133(5):729-38. doi: 10.1043/1543-2165-133.5.729.

5. Bokhman JV. Clinic and treatment of cervical cancer. Chisinau: Shtiints;1976. [In Russian].

6. Papanicolaou G, Traut H. Diagnostic value of vaginal smears in carcinoma of uterus. Am J Obstet Gynecol. 1941;42:193-206.

7. Gibb RK, Martens MG. The impact of liquid-based cytology in decreasing the incidence of cervical cancer. Rev Obstet Gynecol. 2011;4(Suppl 1):S2-S11.

8. Sawaya GF. Rightsizing cervical cancer screening: comment on «Cervical cancer screening with both human papillomavirus and Papanicolaou testing vs Papanicolaou testing alone». Arch Intern Med. 2010;170(11):985-6. doi: 10.1001/archinternmed.2010.133.

9. US Preventive Services Task Force, Curry SJ, Krist AH, Owens DK, Barry MJ, Caughey AB, Davidson KW, et al. Screening for Cervical Cancer: US Preventive Services Task Force Recommendation Statement. JAMA. 2018;320(7):674686. doi: 10.1001/jama.2018.10897. 